This is the author's final, peer-reviewed manuscript as accepted for publication. The publisher-formatted version may be available through the publisher's web site or your institution's library.

\title{
A qualitative study of single-trauma and dual-trauma military couples
}

Briana S. Nelson Goff, Laura Irwin, Michelle Cox, Sara Devine, Kali Orrick, Anne Schmitz

\section{How to cite this manuscript}

If you make reference to this version of the manuscript, use the following information:

Nelson Goff, B. S., Irwin, L., Cox, M., Devine, S., Orrick, K., \& Schmitz, A. (2014). A qualitative study of single-trauma and dual-trauma military couples. Retrieved from http://krex.ksu.edu

\section{Published Version Information}

Citation: Nelson Goff, B. S., Irwin, L., Cox, M., Devine, S., Summers, K., \& Schmitz, A. (2014). A qualitative study of single-trauma and dual-trauma military couples. Psychological Trauma: Theory, Research, Practice, and Policy, 6(3), 216-223.

Copyright: (C2014 American Psychological Association

Digital Object Identifier (DOI): doi:10.1037/a0036697

Publisher's Link: http://psycnet.apa.org/journals/tra/6/3/216/

This item was retrieved from the K-State Research Exchange (K-REx), the institutional repository of Kansas State University. K-REx is available at http://krex.ksu.edu 
A Qualitative Study of Single-Trauma and Dual-Trauma Military Couples

\author{
Briana S. Nelson Goff \\ Laura Irwin \\ Michelle Cox* \\ Sara Devine* \\ Kali Orrick* \\ Anne Schmitz* \\ Kansas State University
}

Correspondence may be directed to: Briana S. Nelson Goff, PhD, Professor, School of Family Studies and Human Services, 343K Justin Hall, Manhattan, KS 66506-1403; bnelson@kstate.edu.

At the time this project was completed, Laura Irwin was a graduate research assistant with the Trauma Research, Education, and Consultation at Kansas State University (TRECK) Team; Michelle Cox, Sara Devine, Kali Orrick, and Anne Schmitz, were undergraduate research assistants with the TRECK Team; School of Family Studies and Human Services, 303 Justin Hall, Manhattan, KS 66506-1403.

* Denotes equal contribution as $3^{\text {rd }}$ authors 
A Qualitative Study of Single-Trauma and Dual-Trauma Military Couples

Trauma survivors and their partners may experience unique dynamics due to the ongoing effects of previous trauma exposure and current trauma symptoms. The current qualitative study attempted to compare and contrast single-trauma couples (one partner reports a trauma history or high traumatic load) with dual-trauma couples (both partners report a trauma history or high traumatic load) to further understand the systemic effects on couple functioning in a sample of military couples. Overall, both positive and negative effects from previous trauma on the couple relationship were reported by participants, including increased awareness, communication, support, coping strategies, and trauma-related triggers, with dual-trauma couples reporting more trauma-related triggers and communication problems. Clinical and research implications for further study are described. 
Much of the current literature in the trauma field focuses on the individual who has directly experienced a traumatic event (i.e., the trauma victim or survivor). The person may experience posttraumatic stress disorder (PTSD) symptoms, such as flashbacks, intrusive thoughts about the traumatic event, psychic numbing, sleep disturbances, exaggerated startle response, increased anger, and isolation (American Psychiatric Association [APA], 2000). While the trauma literature has emphasized the individual survivor's symptoms, the systemic effects of trauma on couple and family relationships have received attention only more recently.

Trauma survivors and their spouses or partners often present with unique dynamics due to the ongoing effects of previous trauma. Combat or other military-related traumatic experiences may be particularly challenging for the couple (Dirkzwager, Bramsen, Adèr, \& van der Ploeg, 2005; Ruger, Wilson, \& Waddoups, 2002), contributing to secondary traumatic stress symptoms in partners (Figley, 1983, 1995; Nelson Goff \& Smith, 2005) and impaired couple relationship functioning (Cook, Riggs, Thompson, Coyne, \& Sheikh, 2004; Dirkzwager et al., 2005; Mikulincer, Florian, \& Solomon, 1995; Riggs, Byrne, Weathers, \& Litz, 1998; Solomon, Waysman, Belkin, Levy, Mikulincer, \& Enoch, 1992; Solomon, Waysman, Levy, et al., 1992; Whiffen \& Oliver, 2004). Recent research on the impact of military deployments to Iraq and Afghanistan since 2003 has found additional support for the negative impact of soldiers’ symptoms on spouses’ individual symptoms and marital satisfaction (Allen, Rhoades, Stanley, \& Markman, 2010; Nelson Goff, Crow, Reisbig, \& Hamilton, 2007, 2009; Renshaw, Rodrigues, \& Jones, 2008, 2009).

One area that has received relatively minimal attention in clinical and empirical literature is the distinction between "single-trauma” and "dual-trauma” couples. Single-trauma couples have been described as couples in which only one partner has experienced a history of trauma 
(Nelson, Wangsgaard, Yorgason, Higgins Kessler, \& Carter-Vassol, 2002). In comparison, dualtrauma couples are described as "couples in which both partners have experienced a trauma, or multiple traumas, which continue to impact their individual and relationship functioning” (Balcom, 1996, p. 432). Clinical descriptions of single-trauma couples include dynamics such as polarized emotional roles, extreme pursuer-distancer patterns, secrecy surrounding the trauma, individual trauma symptoms and issues in both partners, parentification of the nontraumatized partner, and impacts on other subsystems (Nelson et al., 2002). Issues of power and control, competition between partners, external boundary ambiguity, trauma-related symptoms, survivor guilt, preoccupied-dismissing patterns, and minimizing the effects of past trauma experiences on current behaviors may be patterns observed in dual-trauma couples. A limitation identified by Nelson and colleagues was that the descriptions provided were based on clinical observations and not empirical findings; they emphasized the need for further empirical study of these patterns in single- and dual-trauma couples.

The concept of complex trauma is pertinent to the study of trauma in couples. Complex trauma has specifically been defined as the result of exposure to severe stressors that are repetitive and prolonged, involve harm or abandonment by caregivers or other ostensibly responsible adults, and occur at developmentally vulnerable times in the victim's life, such as early childhood or adolescence (Courtois \& Ford, 2009; Spermon, Gibney, \& Darlington, 2009). Consequences of complex trauma may result in changes in the mind, emotions, body, and relationships and may include symptoms such as dissociation, somatic distress, relationship alienation, or emotional dysfunction (Courtois \& Ford, 2009). Similarly, the term polyvictimization (Finkelhor, Ormrod, \& Turner, 2007; Finkelhor, Ormrod, Turner, \& Holt, 2009) has primarily focused on multiple victimization in children, while "polytrauma” has most 
recently been used to describe the effects of a combination of traumatic brain injury (TBI) and PTSD in veterans returning from Iraq and Afghanistan.

Although these terms have garnered increased attention in the literature, they appear to be focused on multiple "types” of traumatic experiences, rather than the "number" of or cumulative effects from multiple traumatic experiences reported by participants. To date, one publication (Kolassa, Ertl, Eckart, Kolassa, Onyut, \& Elbert, 2010) has suggested that “traumatic load,” or the effect of experiencing higher numbers of different lifetime traumatic events, may be a root cause of both chronicity and severity of PTSD symptoms. However, the concept of "traumatic load” has not been previously assessed with regard to couples where only one partner reports a high traumatic load and couples where both partners report a high traumatic load history.

\section{Conceptual Frameworks}

The current study utilized the Couple Adaptation to Traumatic Stress (CATS) Model (Nelson Goff \& Smith, 2005) and the Couple Adaptation to Traumatic Stress-Revised (CATS-R) Model (Oseland, Schwerdtfeger, \& Nelson Goff, in review) as the primary conceptual frameworks. These empirically-informed models describe the mechanisms by which a primary trauma survivor's level of functioning or trauma symptoms will set in motion a systemic response with the potential for the development of secondary traumatic stress symptoms (Figley, 1983, 1998) in the other partner. Conversely, symptoms of secondary trauma in the partner may intensify symptoms of primary trauma in the survivor. Furthermore, adaptation to traumatic stress in the couple dyad involves three primary components: individual level of functioning of both partners, predisposing factors and resources, and couple functioning. The models suggest that individual symptoms in primary and secondary partners affect couple relationship functioning, a primary focus of the current study. 
Given the need for additional research on the systemic effects of trauma in single-trauma and dual-trauma couples, the CATS-R Model (Oseland et al., in review) is used here to provide the framework for understanding the impact of trauma in couples in which only one partner reports a trauma history or high traumatic load (single-trauma couples) and couples in which both partners report a high traumatic load (dual-trauma couples). To date, the literature describing single-trauma and dual-trauma couples has been predominantly clinical and anecdotal (Balcom, 1996; Nelson et al., 2002). The current study attempts to provide preliminary analysis of a sample of single-trauma and dual-trauma couples to further understand the systemic effects on couple functioning.

\section{Method}

\section{Participant Characteristics}

All 22 participants (11 male soldiers and 11 female partners) were married to their partner at the time of data collection. All deployed soldiers reported only one previous deployment to Iraq; three female partners reported a previous military deployment, including one with a previous OIF deployment, but none of the female partners were currently in the military. The average length of deployment for the soldiers was 9.18 months $(S D=4.77)$. (Military rank was inadvertently omitted from the original data collection as a demographic variable question.) Groups did not differ with regard to age of soldiers or their partners, average length of relationship, ethnicity, employment, income, or length of deployment. See Table 1 for additional demographic and quantitative data. 
Table 1

Demographic Statistics

Single-Trauma Couples

$(n=5)$
Dual-Trauma Couples

$$
(n=6)
$$

Soldiers $\quad$ Spouses $\quad$ Soldiers $\quad$ Spouses

Mean Length of Marriage (years)

$$
6.72(S D=8.3)
$$

$5.55(S D=4.8)$

Annual Net Income

$<\$ 30,000$

1

3

$\$ 30,000-39,000$

2

3

$\$ 40,000-59,000$

0

0

$>\$ 60,000$

2

0

Mean Age (years)

32.6

27.2

33.5

30.5

$$
(S D=8.1)
$$

$(S D=7.3)$

$(S D=5.5)$

$(S D=4.6)$

Ethnicity

European American

African American

Native Am/Alaska Native
4

1

0
3

1

1
6

0

0
5

0

1

Education Level

Completed High School

Some College

College Degree
1

3

0
2

2

1
0

1

1

2 
Graduate Degree

Employment

Employed full or part-time

Unemployed

Student/Homemaker

Total Number of Marriages

1

2

3 or more

TEQ Total Scores ***

PPTSD-R Scores **

TSC-40 Scores **

DAS Scores
1

0

5

0

0

4

1

0

9.80

$(S D=1.3)$

40.00

$(S D=15.2)$

26.50

$(S D=21.9)$

118.20

$(S D=20.1)$

3

0

2

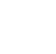

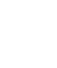


civilian traumas. Figure 1 shows the types of traumatic events experienced by the participants in the current study.

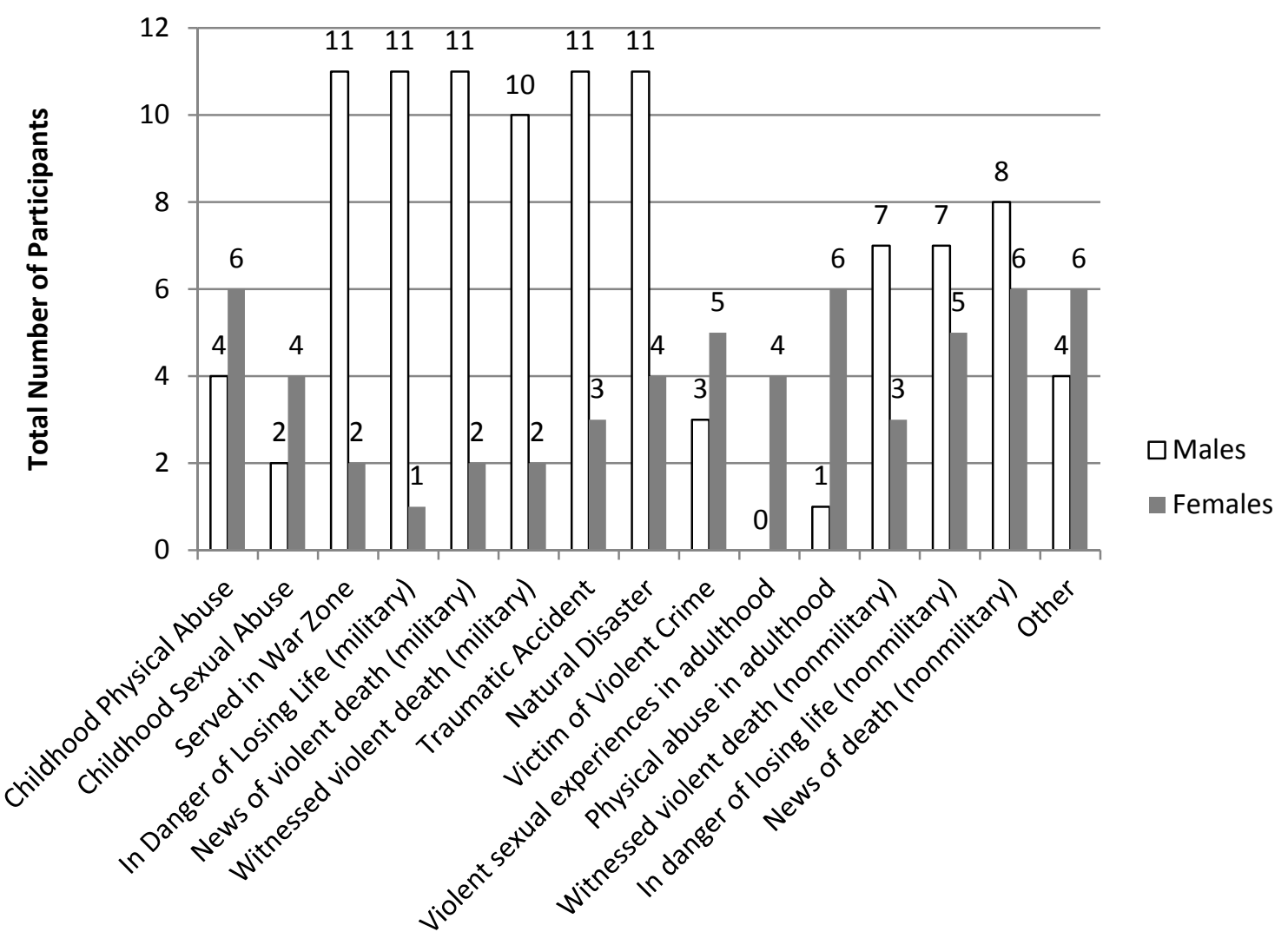

Figure 1: Types of Traumatic Events Experienced by Participants

\section{Data Collection}

The study reported here is part of a larger study of couples conducted by the TRECK (Trauma, Research, Education, and Consultation at Kansas State University) Team. Research participants consisted of 50 couples in two small cities in the Midwest that neighbor two Army posts: Fort Riley, Kansas and Fort Leavenworth, Kansas. The 50 couples were recruited from the local communities through a variety of methods, including publicly posted flyers and newspaper announcements; referral from Army Family Readiness Groups (FRGs), installation chaplains, and other local military contacts; and referral by other research participants. Our goal was to develop a better understanding of how participants themselves viewed the impact of deployments 
on their relationship, and how they may have adapted to the stress of deployment. The sample consisted primarily of male active duty enlisted soldiers and officers, most of whom served in Operation Iraqi Freedom (OIF), and their female partners. Few Guard/Reserve soldiers and no current female soldiers elected to participate. Data collection in the original study began August 25, 2004, and concluded June 20, 2005. Military deployment to Iraq or Afghanistan was a criterion for participation and couples volunteered to participate. All study participants were 18 years of age or older, had been in their current relationship for at least one year, and denied current substance abuse or domestic violence during an initial telephone screening. Each couple that completed the interview process received $\$ 50$ for their participation. The research procedure was approved by the university’s Institutional Review Board. Military Institutional Review Board approval was not obtained because participant recruitment and procedures did not occur directly on the Army posts.

We chose to use a broad definition of "traumatic events" for this study, in order to collect data on a variety of traumatic experiences reported by both partners, including but not limited to only the war-related trauma reported by the soldiers. In this way, it allowed participants to selfidentify the experiences they considered to be traumatic and to identify the range of traumatic experiences reported by participants, not limiting the types of trauma-related data that was included (See Figure 1). Although participants were recruited as couples, because of the sensitive nature of the topic and the possibility that partners might choose not to disclose information with their spouse or partner present, the PI and graduate student members of the research team interviewed each partner separately. Each interview was audiotaped and transcribed verbatim by undergraduate research assistants. The semi-structured interview was guided by 30 open-ended questions that focused on the deployment experience, intra- and inter-personal effects of trauma 
experiences and dyadic functioning. Each interview took between 45 to 90 minutes to complete. Examples of questions include: How is your relationship most affected by your (or your partner's) deployment/previous trauma? How do issues related to your (or your partner's) deployment/previous trauma arise in your relationship? Has your partner ever experienced any traumatic events? How are you (or your partner) most affected by his/her past trauma experiences? (The corresponding author may be contacted to request more specific information about the procedures and the research questions used in this study).

In addition to being interviewed, each participant completed a battery of standardized measures, including the Traumatic Events Questionnaire (TEQ; Vrana \& Lauterbach, 1994), to confirm the history and types of trauma and reported by the participants; the Purdue PostTraumatic Stress Disorder Scale-Revised (PPTSD-R; Lauterbach \& Vrana, 1996), a 17-item measure that corresponds to diagnostic criteria for PTSD (APA, 1994), with three subscales that reflect the three general symptom categories of Re-experiencing, Avoidance, and Arousal; the Trauma Symptom Checklist-40 (TSC-40; Briere, 1996; Briere \& Runtz, n.d.), a 40-item research measure that evaluates symptomatology in adults who have experienced previous traumatic experiences; the Dyadic Adjustment Scale (Spanier, 1976), a 32-item measure designed to assess the quality of the relationship as perceived by both partners. All measures have demonstrated appropriate validity and reliability.

In the current study, affirmative answers on the 17 TEQ items were tallied to provide a “TEQ Total” score, ranging from 0 to 17, with higher scores indicating more types of traumatic events experienced (i.e., greater "traumatic load"). The purpose of the scale is to determine the experience of each participant with various types of trauma that have the potential to produce symptoms of post-traumatic stress (Lauterbach \& Vrana, 1996). The scale used in the current 
study included six items addressing war events (e.g., Did you ever serve in a war zone where you received hostile incoming fire from small arms, artillery, rockets, mortars, or bombs?), two items about traumatic events in childhood (e.g., As a child, were you the victim of physical abuse?), and nine other traumatic events (e.g., Have you been a victim of a violent crime such as rape, robbery, or assault?). The TEQ has shown adequate reliability, with test-retest reliability coefficients ranging from .72 to 1.00 (Vrana \& Lauterbach, 1994).

The current study included an analysis of selected interview transcripts, chosen to reflect varying levels of marital satisfaction in order to allow a broad understanding of the impact of deployment and trauma in couples with high traumatic load in one partner ("single-trauma couples” [STC]) compared to couples with high traumatic load in both partners (“dual-trauma couples” [DTC]). From the original group of 50 couples, qualitative interview data from 11 couples (11 male soldiers and 11 female partners) were selected for further analysis ( $n=5$ STC; $n=6$ DTC). In the STC group, the soldiers in the group reported a TEQ Total score of 9 or higher (i.e., a history of 9 or more separate traumatic experiences, suggesting a high "traumatic load”); their female partners scored 2 or fewer on the TEQ, suggesting a low "traumatic load.” For the DTC group, at least one partner reported a TEQ Total score of 9 or higher and the other partner reported a score of at least 6 or higher (indicating a high "traumatic load” for both partners). The DTC group included four soldiers with TEQ Total scores that were equal to or higher than their female partners and two female partners who reported higher TEQ Total scores than their soldier spouse.

\section{Analytic Strategy}

The purpose of the current study was to explore the lived experience of couples in which one or both partners have directly suffered a traumatic event. Therefore, a phenomenological 
perspective was used, employing a continuous cycle of inductive and deductive qualitative data analysis, referred to as retroduction (Burr, 1973). By relying upon pre-existing theory to guide the view of real world experiences, the use of a retroduction approach has been identified as a vital process to theory building and theory testing (Burr, 1973). While qualitative research is often inductive in nature, with analysis being data-driven, it also is common for analysis to include elements of deduction, in which analysis is theory-driven and data are analyzed according to an established framework (Patton, 2002). The use of the CATS-R Model (Oseland et al., in review) served as a basic framework from which to begin data analysis, while offering flexibility for new themes to emerge. To address the need for convergence, the process of determining what variables, or "themes," fit together (Patton, 2002), the faculty PI identified the primary themes from the CATS-R Model (e.g., adjustment, conflict, awareness, secrecy, sexual problems, triggers). Additional themes emerged during the analysis process, resulting in 41 total theme codes utilized in the data analysis, including both positive and negative variables (e.g., increased and decreased communication, increased and decreased avoidance).

Analysis of the data began after the transcripts of the 22 participants were compiled based on identification of traumatic load and group (STC or DTC) described previously. Prior to beginning the data analysis, research team members were trained by the faculty PI. After the training, team members independently read and coded the transcripts of all 22 interviews by interpreting the meaning they deduced from each transcript, matching the content of the interviews with the identified themes. The use of multiple coders allowed for the triangulation or convergence of several perspectives that enhanced the trustworthiness and credibility of the data interpretations. The research team met for two to three hours approximately every other week over a four-month period of time to share their interpretations of the data and to develop the 
themes that captured the essence of participants' experiences. This process continued until each team member had coded all 22 transcripts. In the final stage of data analysis, the faculty PI and graduate research assistant reviewed and triangulated the identified themes, transcript memos and verbatim evidence from the original transcripts to identify the overall emergent themes and sub-themes that reflected the essence of the participants' phenomenological experiences. To conclude the analysis, the team identified the strongest of the themes, based upon breadth and depth and identified quotes that served as theme exemplars (Patton, 2002). Thus, substantive significance, the method by which qualitative findings are evaluated for scientific merit, similar to that of statistical significance for quantitative data (Patton, 2002), was determined through the use of several methods of triangulation (e.g., multiple coders and team consensus) and through consensual validation by team members. Based on individual member coding and group consensus, the final themes described here consisted of the most frequently identified and most salient themes of the impact of deployment and other trauma experiences had on respondents, their partners, and the dyadic relationship.

\section{Results}

\section{Common Themes}

Data from the qualitative interviews were analyzed for common themes. In the analysis, group and gender provided a basis for comparison. The primary themes will be described below, including the total number and gender of the participants for primary themes, supporting quotes, and participant code numbers for each quote (e.g., $1 \mathrm{M}=$ Couple \#1, male partner; $4 \mathrm{~F}=$ Couple \#4, female partner). Table 1 provides a summary of the qualitative data results.

Table 1

Summary of Results 


\begin{tabular}{|c|c|c|}
\hline & Single-Trauma & Dual-Trauma \\
\hline Themes & Couples & Couples \\
\hline
\end{tabular}

Increased Awareness

Support

Coping Strategies

Communication Problems

Trauma Triggers

Positive Communication
$\mathrm{X}$

$\mathrm{X}$

$\mathrm{X}$

X

X

$\mathrm{X}$

$\mathrm{X}$

X

X

Three themes emerged that were common to both single-trauma couples (STC) and dualtrauma couples (DTC): awareness, support and coping strategies. Awareness was identified by both male and female participants (21 of the 22 participants), and was often used to describe traumatic events of either the participants or their spouse, as well as the experience of the soldiers’ deployment. Participants in both groups described “shared experiences” or increased understanding of nonverbal cues and behaviors rather than direct communication or overt discussion about their traumatic experiences. Other participants reported awareness about how their or their spouse's previous trauma experiences had impacted them personally or had affected their relationship. Similarly, support was described by 20 of the 22 participants, who identified support in terms of resources provided by their spouses, such as letters, care packages, or assistance. It should be noted that participants discussed support of the deployed soldier more than support for themselves or the civilian spouse. Finally, coping strategies were identified as a primary theme for 20 of the 22 participants. The participants in both groups shared various 
methods for coping with past traumas and/or deployments and in terms of their relationship with their spouse. Although some coping strategies could be viewed as strengths or positive methods (e.g., faith, support from family and friends, counseling), other coping strategies could be viewed as more negative, such as withdrawal (reported by more males) or efforts to stay busy (reported by female partners):

Before we were stressed out about going and we just pulled apart from each other, which I think in a way was good, because with being apart for a year like that it's, you don't want to be all cuddly, and all of a sudden, one day you're gone. So you just kinda over a couple of months, you distance yourself in preparation for being apart... I try not to think about it. I guess to me it wasn’t very stressful or traumatic. Which is probably not a very good thing, but like I said, but I don’t wanna think about. (15M)

\section{Dual-Trauma Couple Themes}

Within the DTC group, two unique primary themes were identified: communication problems and trauma triggers. Communication problems were identified by 11 of the 12 participants in the DTC group, compared to only 4 participants in the STC group. Partners described not sharing information, avoiding direct discussions of previous traumas, and difficulty expressing emotions. Although many participants reported understanding that soldiers were expected to not directly discuss deployment, participants in this group described problems with their communication that went beyond the specific deployment experiences. In addition, while both partners might have been aware of the trauma experiences of the other partner, there often was an avoidance or refusal by one or both partners to discuss their previous trauma experiences, a pattern that involved omitting information that could be hurtful or difficult for the other person 
to handle. The following illustrates participants' experiences with patterns of avoidance in their communication:

We try not to talk about the deployment ‘cause she doesn’t wanna know. I understand that, too, but she doesn't wanna know what I went through...She doesn't need to hear it, but, they say what happens in Iraq should stay in Iraq. (15M)

Most of the time we just shut it out. We don't talk about it. That's what the problem is, we don’t solve it. It just goes on the next day, next day and ain’t never figured out how to solve it yet. (45 M)

Trauma-related triggers were reported by 9 of the 12 participants in the DTC group, compared to only 5 STC group participants. This primary theme referred to the effects of traumatic events on their daily lives. Both male and female participants described startle responses they observed in their partners, related to the war deployments as well as other previous traumas. How participants dealt with these triggers is depicted below:

I've seen this grown man jump to the ground. I've seen him in a corner. I've seen things I don't even want to see. About a month and a half before they left again, it started all over again. (43F)

There have been things that I did, like sneaking up behind her and scaring her. Her mother's talked to me about what used to happen with her ex-husband...There are still lots of things that I don’t know. And she probably will never tell me. (6M)

\section{Single-Trauma Couple Themes}


The STC group participants reported primarily positive themes or strengths. Positive communication was described by 7 of the 10 STC group participants (and only 3 of the DTC participants) and referred to addressing issues up front, taking the other's perspective, and an enhanced sense of connection. Participants also emphasized the importance of maintaining the lines of communication while they were apart during the deployment. The following excerpt is a description of one participant's communication with his spouse:

We usually just sit and talk about it. 'Cause, we both, you know, in our past we've had bad relationships. And we both notice ok, if we just sit and talk about it, it would be a lot better than me not talking about it or you not talking about it and then both of us being pissed off and nothing get resolved. But we have a very open communication. (19M)

\section{Discussion}

While similarities of certain themes such as awareness, support, and coping emerged between single-trauma and dual-trauma couple groups in this study, there also were a number of differences. Single-trauma couples reported primarily positive relationship themes, while dualtrauma couples reported a mix of strengths and problem areas, including trauma-related triggers and communication problems. While other research has found that triggers, or reminders of previous trauma experiences, affect the couple relationship (Henry et al., 2011), the current study found it to be more common in both male soldiers and female partners of dual-trauma couples only. Similarly, communication in dual-trauma couples may be impaired through their attempts to avoid direct discussion of either previous or current trauma symptoms (e.g., flashbacks and startle responses) of both partners. This avoidance may reduce couples’ awareness and understanding of the impact of prior trauma, both individually and systemically. The term “protective buffering,” (Coyne \& Smith, 1991; Langer, Brown, \& Syrjala, 2009) may be a 
helpful term to describe the pattern of secrecy and avoidance that occurs in dual-trauma couples (Nelson et al., 2002), as well as in military couples more generally (Joseph \& Afifi, 2010). In other words, one or both partners may purposefully omit information about previous trauma that could be particularly painful to hear or because they do not know how their partner will respond to their disclosure. Instead of risking a possible negative reaction from their spouse, survivors continually avoid any discussion of the trauma with their partner, just as they use other avoidance symptoms to control the reminders of the trauma for themselves. The result may be the very relationship problems (i.e., impaired communication and relationship functioning) that they were attempting to prevent through their avoidance and protective buffering.

Dual-trauma couples were also distinguished by both spouses’ relatively low relationship satisfaction (DAS) and high trauma symptom (PPTSD-R and TSC-40) scores. Although the DTC scores were not statistically different from STC couples (due to sample size), these differences between the groups should be further explored. In addition, each spouse reported a history of multiple, complex traumatic events: childhood physical and sexual abuse, and rape, domestic violence, or other violent crime as an adult (including two spouses who reported assaults that occurred during their husband’s deployment).

In the current study, the trauma-related triggers, communication problems, fear, and PTSD/trauma symptoms reported by the DTC group participants undoubtedly have a critical impact on their relationship functioning, although both DTC and STC participants ranged from very dissatisfied to very satisfied in their relationships. Three of the six female partners and two of the six male partners in the DTC group reported relationship satisfaction scores below the clinical cutoff score of 100 (Eddy, Heyman, \& Weiss, 1991); only one couple in the STC group reported low relationship satisfaction scores. Moreover, many more DTC participants (8 of 12) 
had been married previously, compared to only 1 of 10 STC participants. As a whole, the DTC group appeared to be more at risk for relationship problems and less able to prevent negative effects of trauma on their relationship than were STC participants.

\section{Limitations and Future Research Implications}

There are several limitations in the current study. Participants were predominantly White and the sample consisted primarily of active duty male soldiers and their female spouses. In addition, all the soldiers had only been deployed to Iraq once during 2003-2004, so the impact of multiple deployments on participants' current marital adjustment is unknown. The participants in the current study were relatively young and the results are indicative of fairly well-functioning couples, as indicated by their relationship satisfaction scores at the time data were collected. Furthermore, information about pre-existing disorders or diagnoses (such as PTSD) was not available, nor was the sample clinically-based. Although the current sample was recruited from the community, research with clinical samples is needed to assess whether the themes in the current study also pertain to clinical couples, particularly when there is a PTSD or other traumarelated diagnosis. Quantitative research that addresses both different demographic groups and other quantitative variables (i.e., trauma and other symptom levels, couple and family functioning variables) would be beneficial.

Themes differentiating single- and dual-trauma couples that had been identified in Nelson et al. (2000) did not emerge in this sample (e.g., polarized emotional roles in STC, issues of power and control and competition in DTC), nor did the themes of boundary issues (Faber, Willerton, Clymer, MacDermid, \& Weiss, 2008) and sexual intimacy problems (Nelson Goff et al., 2006, 2007; Whiffen \& Oliver, 2004). However, it should be noted that couples in the current 
study were not asked directly about all of these specific areas, although they were included as possible qualitative codes in the analysis.

A final limitation involved the methods used in the study. While joint couple interviews may have provided more systemic information about the couple functioning and interactions, there were also reasons for conducting separate individual interviews with each partner, including to assure each individual’s privacy. In addition, longitudinal qualitative and quantitative research is needed to explore how previous trauma experiences and current trauma symptoms affect the marital stability, parenting skills, and other systemic variables of DTC couples. It is also necessary for further quantitative research to build on the qualitative results of the current study, specifically to address communication skills, coping strategies, and specific support mechanisms that may be unique to STC and DTC. Further, understanding how communication problems and trauma-specific triggers may directly impact individual and couple functioning in trauma survivors also should be further delineated.

\section{Implications for Clinical Services for Military Couples Facing Deployment}

Although the current sample was recruited from the community, there are important implications of this study’s findings for clinical intervention. Issues related to communication, trauma triggers, relationship roles, intimacy, conflict and emotional reactions such as anger and fear need to be evaluated and understood within a trauma framework (Johnson, 2002; Nelson Goff \& Smith, 2005; Oseland et al., in review). A phase-oriented culturally responsive couple therapy approach, such as that developed by Basham (2008), that addresses the disruption of secure attachments and affect dysregulation could be effective with trauma survivors and military couples post-deployment. In addition, emphasizing the importance of awareness, support, communication and coping, as well as recognizing potential effects when both partners 
have a history of high traumatic load, are important elements to include in trainings and military briefings in preparing families for deployment. Systemic therapies also should not be viewed as "adjunct" to other individual trauma treatments (e.g., cognitive behavioral therapy, exposure therapy); however, further research is needed to define effective systemic therapies for trauma survivors and their support systems.

We can no longer consider trauma to be a strictly individual experience. The systemic repercussions of these events on partners and on couple and family relationships require attention. The effects of trauma in single-trauma and dual-trauma couples need to be further explored to understand how trauma may affect these couples in similar or varying ways. For military couples, the stress of war deployment impacts not only those serving in the military but also their partners, who maintain their lives while waiting for the safe return of their service members.

\section{References}

Allen, E. S., Rhoades, G. K., Stanley, S., M., \& Markman, H. J. (2010). Hitting home: Relationships between recent deployment, posttraumatic stress symptoms, and marital functioning for Army couples. Journal of Family Psychology, 24, 280-288. doi: 10.1037/a0019405

American Psychiatric Association. (2000). Diagnostic and statistical manual of mental disorders ( $4^{\text {th }}$ ed., text rev.). Washington, DC: Author.

Balcom, D. (1996). The interpersonal dynamics and treatment of dual trauma couples. Journal of Marital and Family Therapy, 22, 431-442. doi: 10.1111/j.1752-0606.1996.tb00218.x 
Basham, K. (2008). Homecoming as safe haven or the new front: Attachment and detachment in military couples. Journal of Clinical Social Work, 36, 83-96. doi: 10.1007/s10615-0070138-9

Briere, J. (1996). Psychometric review of Trauma Symptom Checklist 33 \& 40. In B. H. Stamm (Ed.), Measurement of stress, trauma, and adaptation (pp. 373-377). Lutherville, MD: Sidran Press.

Briere, J., \& Runtz, M. (n.d.) Trauma Symptom Checklist 33 and 40: TSC-33 and TSC-40. Retrieved April 5, 2006, from http://www.johnbriere.com/tsc.htm.

Burr, W. R. (1973). Theory construction and the sociology of the family. New York: John Wiley \& Sons.

Cook, J. M., Riggs, D. S., Thompson, R., Coyne, J. C., \& Sheikh, J. I. (2004). Posttraumatic stress disorder and current relationship functioning among World War II ex-prisoners of war. Journal of Family Psychology, 18, 36-45. doi: 10.1037/0893-3200.18.1.36

Courtois, C., \& Ford, J. (2009). Treating complex traumatic stress disorders: An evidence-based guide. New York: Guilford Press.

Coyne, J. C., \& Smith, D. A. F. (1991). Couples coping with a myocardial infarction: A contextual perspective on wives’ distress. Journal of Personality and Social Psychology, 61, 404-412. doi: 10.1037/0022-3514.61.3.404

Dirkzwager, A. J. E., Bramsen, E., Adèr, H., \& van der Ploeg, H. M. (2005). Secondary traumatization in partners and parents of Dutch peacekeeping soldiers. Journal of Family Psychology, 19, 217-226. doi: 10.1037/0893-3200.19.2.217 
Eddy, J. M., Heyman, R. E., \& Weiss, R. L. (1991). An empirical evaluation of the Dyadic Adjustment Scale: Exploring the differences between marital "satisfaction” and “adjustment.” Behavioral Assessment, 13, 199-220.

Faber, A. J., Willerton, E., Clymer, S. R., MacDermid, S. M., \& Weiss, H. M. (2008). Ambiguous absence, ambiguous presence: A qualitative study of military reserve families in wartime. Journal of Family Psychology, 22, 222-230. doi: 10.1037/08933200.22 .2 .222

Figley, C. R. (1983). Catastrophes: An overview of family reaction. In C. R. Figley \& H. I. McCubbin (Eds.), Stress and the family: Coping with catastrophe (Vol. 2, pp. 3-20). New York: Brunner/Mazel.

Figley, C. R. (1995). Compassion fatigue as secondary traumatic stress disorder. In C. R. Figley (Ed.), Compassion fatigue: Coping with secondary traumatic stress disorder in those who treat the traumatized (pp. 1-20). New York: Brunner/Mazel.

Figley, C. R. (Ed.). (1998). Burnout in families: The systemic costs of caring. Boca Raton, FL: CRC Press.

Finkelhor, D., Ormrod, R. K., \& Turner, H. A. (2007). Poly-victimization: A neglected component in child victimization. Child Abuse \& Neglect, 31, 7-26. doi: 10.1016/j.chiabu.2006.06.008

Finkelhor , D., Ormrod, R. K., Turner, H. A., \& Holt, M. (2009). Pathways to poly-victimization. Child Maltreatment, 14(4), 316-329. doi: 10.1177/1077559509347012

Henry, S. B., Smith, D. B., Archuleta, K., Sanders-Hahs, E., Nelson Goff, B. S., Reisbig, A. M. J.,...Scheer, T. (2011). Trauma and couples: Mechanisms in dyadic functioning. Journal of Marital and Family Therapy, 37, 319-332. doi: 10.1111/j.1752-0606.2010.00203.x 
Johnson, S. M. (2002). Emotionally focused couple therapy with trauma survivors:

Strengthening attachment bonds. New York: Guilford Press.

Joseph, A. L., \& Afifi, T. D. (2010). Military wives’ stressful disclosures to their deployed husbands: The role of protective buffering. Journal of Applied Communication Research, 38, 412-434. doi: 10.1080/00909882.2010.513997

Kolassa, I.-T., Ertl, V., Eckart, C., Kolassa, S., Onyut, L. P., \& Elbert, T. (2010). Spontaneous remission from PTSD depends on the number of traumatic event types experienced. Psychological Trauma, 2, 169-174. doi: 10.1037/a0019362

Langer, S. L., Brown, J. D., \& Syrjala, K. L. (2009). Intrapersonal and interpersonal consequences of protective buffering among cancer patients and caregivers. Cancer, 115, 4311-4325. doi: 10.1002/cncr.24586

Lauterbach, D., \& Vrana, S. (1996). Three studies on the reliability and validity of a self-report measure of posttraumatic stress disorder. Assessment, 3, 17-25. doi: $10.1177 / 107319119600300102$

Mikulincer, M., Florian, V., \& Solomon, Z. (1995). Marital intimacy, family support, and secondary traumatization: A study of wives of veterans with combat stress reaction. Anxiety, Stress, and Coping, 8, 203-213. doi: 10.1080/10615809508249373

Nelson, B. S., Wangsgaard, S., Yorgason, J., Higgins Kessler, M., \& Carter-Vassol, E. L. (2002). Single and dual trauma couples: Relationship characteristics and dynamics. American Journal of Orthopsychiatry, 72, 58-69. doi: 10.1037/0002-9432.72.1.58

Nelson Goff, B. S., Crow, J. R., Reisbig, A. M. J., \& Hamilton, S. (2007). The impact of individual trauma symptoms of deployed soldiers on relationship satisfaction. Journal of Family Psychology, 21, 344-353. doi: 10.1037/0893-3200.21.3.344 
Nelson Goff, B. S., Crow, J. R., Reisbig, A. M. J., \& Hamilton, S. (2009). The impact of soldiers’ deployments to Iraq and Afghanistan: Secondary traumatic stress in female partners. Journal of Couple and Relationship Therapy, 8, 291-305. doi:

10.1080/15332690903246085

Nelson Goff, B. S., Reisbig, A. M. J., Bole, A., Scheer, T., Hayes, E., Archuleta, K. A.,...Smith, D. B. (2006). The effects of trauma on intimate relationships: A qualitative study with clinical couples. American Journal of Orthopsychiatry, 76, 451-460. doi: 10.1037/00029432.76 .4 .451

Nelson Goff, B. S., \& Smith, D. (2005). Systemic traumatic stress: The Couple Adaptation to Traumatic Stress model. Journal of Marital \& Family Therapy, 31, 145 - 157. doi: 10.1111/j.1752-0606.2005.tb01552.x

Oseland, L. M., Schwerdtfeger, K. L., \& Nelson Goff, B. S. (in review). Clinical application of the Couple Adaptation to Traumatic Stress (CATS) Model: A pragmatic framework for working with traumatized couples. Manuscript submitted for publication.

Patton, M. Q. (2002). Qualitative research and evaluation methods ( ${ }^{\text {rd }}$ ed.). Thousand Oaks, CA: Sage.

Renshaw, K. D., Rodrigues, C. S., \& Jones, D. H. (2008). Psychological symptoms and marital satisfaction in spouses of Operation Iraqi Freedom veterans: Relationships with spouses’ perceptions of veterans’ experiences and symptoms. Journal of Family Psychology, 22, 586-594. doi: 10.1037/0893-3200.22.3.586

Renshaw, K. D., Rodrigues, C. S., \& Jones, D. H. (2009). Combat exposure, psychological symptoms, and marital satisfaction in National Guard soldiers who served in Operation 
Iraqi Freedom from 2005 to 2006. Anxiety, Stress \& Coping, 22, 101-115. doi:

$10.1080 / 10615800802354000$

Riggs, D. S. (2000). Marital and family therapy. In E. B. Foa, T. M. Keane, \& M. J. Friedman (Eds.), Effective treatments for PTSD: Practice guidelines from the International Society for Traumatic Stress Studies (pp. 280-301). New York: Guilford.

Riggs, D. S., Byrne, C. A., Weathers, F. W., \& Litz, B. T. (1998). The quality of the intimate relationships of male Vietnam veterans: Problems associated with posttraumatic stress disorder. Journal of Traumatic Stress, 11, 87-101. doi: 10.1023/A:1024409200155

Ruger, W., Wilson, S. E., \& Waddoups, S. L. (2002). Warfare and welfare: Military service, combat, and marital dissolution. Armed Forces \& Society, 29, 85-107. doi: 10.1177/0095327X0202900105

Solomon, Z., Waysman, M., Belkin, R., Levy, G., Mikulincer, M., \& Enoch, D. (1992). Marital relations and combat stress reaction: The wives’ perspective. Journal of Marriage and the Family, 54, 316-326.

Solomon, Z., Waysman, M., Levy, G., Fried, B., Mikulincer, M.,...Bleich, A. (1992). From front line to home front: A study of secondary traumatization. Family Process, 31, 289-302. Spanier, G. B. (1976). Measuring dyadic adjustment: New scales for assessing the quality of marriage and similar dyads. Journal of Marriage and the Family, 38, 15-28.

Spermon, D., Gibney, P., \& Darlington, Y. (2009). Complex trauma, dissociation, and the use of symbolism in therapy. Journal of Trauma \& Dissociation, 10, 436-450. doi:

10.1080/15299730903179083 
Vrana, S., \& Lauterbach, D. (1994). Prevalence of traumatic events and post-traumatic psychological symptoms in a nonclinical sample of college students. Journal of Traumatic Stress, 7, 289-302. doi: 10.1002/jts.2490070209

Whiffen, V. E., \& Oliver, L. E. (2004). The relationship between traumatic stress and marital intimacy. In D. R. Catherall (Ed.), Handbook of stress, trauma, and the family (pp. 139159). New York: Brunner-Routledge. 